\title{
Involvement of nerves and calcium channels in the intestinal response to Clostridium difficile toxin A: an experimental study in rats in vivo
}

\author{
J Sörensson, M Jodal, O Lundgren
}

\begin{abstract}
Background-The involvement of nerves and calcium channels in the intestinal response to Clostridium difficile toxin A (luminal concentration 1 or $15 \mu \mathrm{g} / \mathrm{ml}$ ) was studied in the small intestine of rats in vivo.
\end{abstract}

Methods-Inflammation was quantified by estimating myeloperoxidase (MPO) activity in the intestinal lumen, extravascular accumulation of Evan's blue (EB) in the intestine, and number of red blood cells (RBCs) in veins in histological sections. Intestinal damage was estimated using a histological grading system. In some experiments net fluid transport was recorded using a gravimetric technique.

Results-In acutely denervated intestines, toxin A caused marked destruction of the villi, increased luminal release of MPO activity, and augmentation of intestinal content of EB and venous RBCs. Denervating the intestine 3-4 weeks prior to the actual experiment prevented the development of villus damage and significantly decreased the number of RBCs in intestinal veins in experiments with a low toxin concentration, whereas no effect was demonstrated on luminal MPO activity. Using a high toxin concentration, chronic denervation decreased only the number of RBCs. Pretreatment with hexamethonium (low toxin concentration; acute denervation) attenuated the effect of toxin $A$ on morphology, luminal MPO activity, and number of RBCs. Pretreatment with nifedipine (low toxin concentration; acute denervation) significantly decreased intestinal MPO activity and number of RBCs. Tissue accumulation of EB was not influenced by experimental manipulation. Net fluid transport was measured in experiments exposing the intestinal mucosa to a high toxin concentration. Fluid secretion caused by the toxin was significantly attenuated by intravenous hexamethonium whereas no effect was observed after administration of nifedipine or granisetron.

Conclusions-At a low toxin concentration, intramural reflexes are involved in the inflammatory response whereas axon reflexes contribute to tissue damage. At a high toxin concentration no nervous involvement in the toxin $A$ response was demonstrated except for fluid secretion evoked by the toxin.

(Gut 2001;49:56-65)
Keywords: cholera toxin; enteric nervous system; 5-hydroxytryptamine; myeloperoxidase; red blood cells

Experimental studies have demonstrated that the enteric nervous system (ENS) is of great importance in explaining fluid secretion caused by several intestinal secretagogues, including cholera toxin (CT), the heat stable enterotoxin produced by Escherichia coli, bile salt, and invasive strains of Salmonella typhimurium. ${ }^{1-4}$ These proposals are supported by the findings that placing lidocaine, a local anaesthetic, on the intestinal serosa or administering intravenous hexamethonium, a blocker of nicotinic cholinergic receptors, markedly diminishes fluid secretion caused by the above mentioned secretagogues. The general picture emerging from these studies is that the ENS contains a secretory reflex(es) confined to the intestinal wall ("intramural reflexes") with at least one cholinergic synapse.

Experimental observations also suggest the presence of axon reflexes in the ENS. They are made up of branching afferent fibres connecting the ENS to the central nervous system. Axon reflexes seem to be involved in nervous control of blood flow. Thus noxious mucosal stimuli evoke vasodilatation in the stomach ${ }^{5}$ and in the intestine, ${ }^{6}$ apparently via axon reflexes. On the other hand, they appear not to be involved in fluid secretion evoked by CT or bile salt, for example. ${ }^{78}$

Clostridium difficile is the causative agent of antibiotic associated enterocolitis in animals and humans. It produces two enterotoxins of high molecular weight: toxin $\mathrm{A}$ and toxin $\mathrm{B}$. Both toxins have cytotoxic activity against a variety of cultured cells ${ }^{9}$ and cause death when injected parentally in laboratory animals. ${ }^{10}$ In several reports it has been demonstrated that toxin A but not toxin B evokes an inflammatory response both in the small and large intestine. ${ }^{11}$ However, Riegler and colleagues ${ }^{12}$ reported that toxin B may induce inflammation in the human colon in vitro.

It had been generally assumed that the intestinal inflammatory response to Clostridium difficile toxin A was secondary to the cytotoxic effect of the toxin on enterocytes. Therefore, it came as a surprise when Castagliuolo and colleagues $^{13}$ reported that the secretory and

Abbreviations used in this paper: $\mathrm{CT}$, cholera toxin; EB, Evan's blue; ENS, enteric nervous system; 5-HT, 5-hydroxytryptamine; MPO, myeloperoxidase; RBC, red blood cells; TMB, 3,5,3',5'-tetramethylbenzidine. 
inflammatory responses evoked by exposing the intestinal mucosa of the rat to toxin A was mediated in part via activation of the ENS. The results suggested that the inflammatory response to toxin A was caused by activation of both intramural and axon reflexes.

The present study was performed to further investigate the nervous involvement in the inflammatory response to Clostridium difficile toxin A in vivo. A gravimetric method was used for monitoring fluid transport. The inflammatory response was followed by determinations of neutrophil accumulation in the intestinal lumen, extravasation of Evan's blue albumin in the intestinal tissue, and accumulation of red blood cells (RBCs) in intestinal veins. Two major questions were addressed. Firstly, we wished to confirm the nervous involvement in the inflammatory response reported by Castagliuolo and colleagues. ${ }^{13}$ In particular, we were interested in the possible involvement of axon reflexes in the response. In the study by Castagliuolo et al, evidence for an axon reflex was obtained by use of capsaicin which destroys thin afferent fibres. We used another experimental approach, namely denervating the intestine, by severing the nerves around the superior mesenteric artery and allowing the nerves to degenerate over 4-6 weeks. Furthermore, we studied if nervous involvement was similar when exposing the intestinal mucosa to a low or a comparatively high concentration of toxin $\mathrm{A}$.

Secondly, we have demonstrated that calcium channel blockers of the L-type (nifedipine) diminish fluid secretion evoked by CT or bile salt in part possibly via an influence on the afferent part of the intramural secretory reflex. ${ }^{14}$ In this study therefore we investigated the effect of calcium channel blockers on the inflammatory response to toxin $\mathrm{A}$.

\section{Materials and methods}

ANAESTHESIA AND OPERATIVE PROCEDURES

Experiments were performed on adult male Sprague-Dawley rats, weighing 380-600 g (Alab AB, Stockholm, Sweden). Animals were kept under standardised environmental conditions $\left(22^{\circ} \mathrm{C}, 60 \%\right.$ humidity, artificial light from 0600 to 1800 hours) in the animal quarters for at least seven days prior to experiments. The present experiments were approved by the ethics committee for animal experimentation at Göteborg University.

Anaesthesia was induced with pentobarbital (60 $\mathrm{mg} / \mathrm{kg}$ body weight) intraperitoneally. A tracheal cannula was inserted to assure free airways, and a femoral vein was cannulated for administration of drugs. Arterial pressure was recorded using a pressure transducer (DPT6000 Single-Use Transducer; Peter von Berg Medizinteknik Gmbh, Egelharting, Germany) via a catheter in the femoral artery. This catheter was also used to maintain anaesthesia by continuous infusion of chloralose $(2-4 \mathrm{mg} / \mathrm{ml}$; $0.02 \mathrm{ml} / \mathrm{min}$ ) which was given in a solution containing $138 \mathrm{mM}$ glucose and $33 \mathrm{mM}$ $\mathrm{NaHCO}_{3}$ to prevent dehydration and acidosis during and after surgery. Body temperature was monitored by a rectal thermistor and maintained at $37^{\circ} \mathrm{C}$ using a heated operation table and heating lamp. After tracheotomy, a midline abdominal incision was performed and three $10-15 \mathrm{~cm}$ long jejunal-ileal segments starting $10 \mathrm{~cm}$ below the ligament of Treitz were isolated with intact vascular supply. After denervating acutely the intestinal segments as described below, the segments were returned to the abdominal cavity.

EXTRINSIC DENERVATION OF THE SMALL INTESTINE

In all experiments except those described in the next paragraph, the extrinsic autonomic nervous supply to the intestinal segments was acutely severed. Thus all nerves along the superior mesenteric artery were identified and cut between ligatures, implying that the nerves were divided distal to the sympathetic prevertebral ganglia.

In 10 experiments the intestinal segments were denervated 3-4 weeks prior to the acute experiments. The rats used in these experiments were anaesthetised with methohexital ( $30 \mathrm{mg} / \mathrm{kg}$ body weight intraperitoneally). The abdomen was opened and the superior mesenteric artery identified. The nerves around this vessel were isolated and cut. Furthermore, the vessel was painted with a $10 \%$ phenol solution. After operation the animal was placed in a cage heated with a lamp. After waking up they were brought to the animal quarters and observed repeatedly during the first 24 hours after operation.

DETERMINATION OF EVAN'S BLUE-ALBUMIN CONCENTRATION IN INTESTINAL TISSUE

Thirty minutes before the end of the experiments animals were given Evan's blue (20 $\mathrm{mg} / \mathrm{kg}$ body weight dissolved in $1 \mathrm{ml}$ of saline) intravenously. After the experiments were completed, a catheter was inserted into the supplying superior mesenteric artery and the mesenteric vein was cut open. Tissue was flushed with $20 \mathrm{ml}$ of a warm solution of physiological saline to rinse Evan's blue from the vasculature. A $2-3 \mathrm{~cm}$ long portion of both the control segment and toxin segment were obtained, rinsed in saline, dried on filter paper, and weighed and frozen for subsequent determination of Evan's blue-albumin.

Determination of Evan's blue in tissue biopsies was performed in the following way. Tissue samples were thawed and placed in a tube with $4 \mathrm{ml}$ of formamide and incubated for 24 hours in a shaking water bath at $50^{\circ} \mathrm{C}$, as described by Gamse and colleagues. ${ }^{15}$ Colorimetric measurement of the solution was performed in a Stasar spectrophotometer (Gilford Stasar III) at $612 \mathrm{~nm}$, the peak absorption wavelength of Evan's blue. Three measurements were performed on each sample and the mean value was used for estimating the amount of Evan's blue from a standard curve.

ESTIMATION OF MYELOPEROXIDASE IN THE INTESTINAL LUMEN

Myeloperoxidase activity (MPO) was measured in aliquots of intestinal fluid according to Schierwagen and colleagues, ${ }^{16}$ who 
modified the assay originally proposed by Bradley and colleagues. ${ }^{17}$ Briefly, the frozen samples of fluid from the intestinal lumen were thawed at room temperature and suspended in a $0.05 \mathrm{M}$ potassium phosphate buffer, $\mathrm{pH} 6.0$, containing $0.5 \%$ HTAB (hexadecyltrimethyl ammonium bromide; JT Baker, BV Deventer, Holland). The suspension was sonicated for 10 seconds and centrifuged at $1700 \mathrm{~g}$ for $30 \mathrm{~min}$ utes at $4^{\circ} \mathrm{C}$. The supernatant $(1 \mathrm{ml})$ was incubated at $60^{\circ} \mathrm{C}$ for two hours in a water bath. Finally, the suspension was centrifugated once again at $10000 \mathrm{~g}$ for five minutes at $4^{\circ} \mathrm{C}$.

MPO activity was assayed by measuring $\mathrm{H}_{2} \mathrm{O}_{2}$ dependent oxidation of 3,5,3',5'tetramethylbenzidine (TMB; Merck, Darmstadt, Germany; Suzuki et al 1983). In its oxidised form TMB has a blue colour which can be measured spectrophotometrically at $650 \mathrm{~nm}$. The reaction mixture consisted of $100 \mu \mathrm{l}$ of intestinal fluid sample, $100 \mu \mathrm{l}$ TMB (final concentration $0.16 \mathrm{mM}$ ) dissolved in dimethylsulphoxide (Merck) and $800 \mu \mathrm{H}_{2} \mathrm{O}_{2}$ (Merck; final concentration $0.24 \mathrm{mM}$ ) diluted in $0.08 \mathrm{M}$ potassium phosphate buffer, $\mathrm{pH}$ 5.4. The reaction was performed in a $1 \mathrm{ml}$ cuvette and the mixture was incubated for five minutes at $37^{\circ} \mathrm{C}$ and stopped with $25 \mu \mathrm{l}$ of bovine catalase (Merck; final concentration $13.6 \mu \mathrm{g} / \mathrm{ml}$ ). Spectrophotometric measurements of fluid were made at $650 \mathrm{~nm}$ with a Gilford Stasar III spectrometer. Concentrations were expressed in units (U) per $\mathrm{ml}$ as estimated from a standard curve using known amounts of MPO purchased from Sigma Chemicals (St Louis, Missouri, USA). U is defined in terms of rate of increase in absorbance at $470 \mathrm{~nm}\left(25^{\circ} \mathrm{C}, \mathrm{pH}\right.$ 7.0).

GRAVIMETRIC METHOD FOR MEASURING

INTESTINAL NET FLUID TRANSPORT

Intestinal fluid transport was estimated on one isolated jejunal-ileal segment about $7 \mathrm{~cm}$ long. Net fluid transport was measured with a gravimetric technique developed in our laboratory and described in detail by Cassuto and colleagues. ${ }^{18}$ In contrast with our other experiments, the small intestine, except the segment under study, and the colon were extirpated. The acutely denervated intestinal segment was placed on a specially designed plastic balance suspended 3-5 $\mathrm{mm}$ above the abdominal wall and connected to a force displacement transducer (Grass FT03C), allowing continuous recording of changes in intestinal weight. Net fluid transport across the intestinal epithelium (reflected as changes in intestinal weight) was recorded continuously by connecting the force displacement transducer to a Grass polygraph. To minimise evaporation, the intestinal segment was carefully covered by a plastic film, and the rat was placed in a plastic cage in which the temperature was kept constant at $37^{\circ} \mathrm{C}$. The head of the rat was placed outside the cage wall to allow the animal to breathe air at room temperature. The measured rate of fluid transport was related to the serosal surface area of the investigated segment.
Table 1 Scoring system for histological damage seen in intestinal segments after exposure to Clostridium difficile toxin $A$

\begin{tabular}{ll}
\hline Score & Damage \\
\hline 0 & None \\
1 & Destruction of villus tips \\
2 & Destruction of distal half of villi \\
3 & Complete destruction of villi \\
\hline
\end{tabular}

HISTOLOGICAL PROCEDURES

At the end of the experiments, biopsies were taken from the intestinal segments for histological examination. Tissues were fixed in $4 \%$ buffered formalin, embedded in paraffin, sectioned, and stained with haematoxylineosin. Histological damage evoked by the toxin was judged according to a four point scoring system (table 1). Furthermore, the number of venous vessels containing RBCs were counted in $400 \mu \mathrm{m}$ long parts of three biopsies from each intestinal segment.

\section{EXPERIMENTAL PROCEDURES}

Two types of experiments were performed.

(1) MPO and Evan's blue experiments

Plastic tubings were placed in the ends of the three segments. After a control period of 30 minutes, one of the segments was flushed with $2 \mathrm{ml}$ of physiological saline. The solution leaving the distal end was collected in a preweighed plastic tube for subsequent determination of MPO concentration. The segment was extirpated and prepared for histology.

One of the remaining segments was exposed to $1 \mathrm{ml}$ of a saline solution containing Clostridium difficile toxin A 1 or $15 \mu \mathrm{g} / \mathrm{ml}$ in a randomised fashion. The other segment was exposed to saline solution. One, two, and three hours after exposing the intestinal mucosa to the toxin the segments were flushed with $2 \mathrm{ml}$ of saline and the solution leaving the segments was collected as described above.

Two hours 30 minutes after the start of the experiments, Evan's blue (20 mg/kg body weight) was injected intravenously. Thirty minutes later the two segments were extirpated for estimation of contents of Evan's blue, as described above.

The drugs tested in these experiments (hexamethonium and nifedipine) were given before exposing the intestinal segment to the toxin and then repeatedly every 45 minutes throughout the experiment.

\section{(2) Gravimetric experiments}

The intestinal lumen was filled with a modified Krebs-Henseleit solution. After recording net fluid transport for 30-45 minutes, Clostridium difficile toxin A $(15 \mu \mathrm{g} / \mathrm{ml})$ dissolved in the Krebs-Henseleit solution was placed in the intestinal lumen. The toxin regularly evoked pronounced net fluid secretion within two hours. Drugs to be tested (hexamethonium, nifedipine, and granisetron) were then injected intravenously.

\section{SOLUTIONS AND DRUGS}

The modified Krebs-Henseleit solution used in all experiments contained the following (in 
Table 2 Histological grading of villus damage and number of veins containing red blood cells $(R B C)$ in the different series of the present study. Hexamethonium and nifedipine experiments were performed on acutely denervated intestinal segments. For details of measurements see table 1 and text

\begin{tabular}{|c|c|c|c|c|}
\hline \multirow[b]{2}{*}{ Series } & \multicolumn{2}{|c|}{ Villus damage } & \multicolumn{2}{|c|}{ Venous $R B C$} \\
\hline & Control & $\operatorname{Toxin} A$ & Control & Toxin $A$ \\
\hline \multicolumn{5}{|l|}{ Toxin $\mathrm{A}, 1 \mu \mathrm{g} / \mathrm{ml}$} \\
\hline Acutely denervated (6) & $0.2(0.2)$ & $2.1(0.3)^{\mathrm{a}}$ & $2.5(0.9)$ & $10.8(1.2)^{\mathrm{a}}$ \\
\hline Chronically denervated (5) & $0(0)$ & $0.2(0.2)^{\mathrm{b}}$ & $3.3(1.3)$ & $5.2(1.8)^{\mathrm{a} b}$ \\
\hline Hexamethonium (5) & $0.3(0.3)$ & $1.2(0.4)^{\mathrm{abc}}$ & $3.3(0.9)$ & $3.4(1.3)^{\mathrm{b}}$ \\
\hline Nifedipine (6) & $0(0)$ & $1.8(0.5)^{\mathrm{ac}}$ & $4.7(1.4)$ & $3.3(0.7)^{\mathrm{b}}$ \\
\hline \multicolumn{5}{|l|}{ Toxin $\mathrm{A}, 15 \mu \mathrm{g} / \mathrm{ml}$} \\
\hline Acutely denervated (6) & $0(0)$ & $2.8(0.2)^{\mathrm{a}}$ & $3.4(1.2)$ & $8.8(1.1)^{\mathrm{a}}$ \\
\hline Chronically denervated (5) & $0(0)$ & $2.2(0.3)^{\mathrm{a} \mathrm{d}}$ & $2.7(0.5)$ & $4.2(1.0)^{\mathrm{b}}$ \\
\hline
\end{tabular}

Numbers in parentheses indicate number of observations.

${ }^{\text {aS }}$ Statistically significant compared with control; ${ }^{b}$ statistically significant compared with acutely denervated; 'statistically significant compared with chronically denervated; ${ }^{\mathrm{d}}$ statistically significant compared with corresponding group of toxin $\mathrm{A}, 1 \mu \mathrm{g} / \mathrm{ml}$.

$\mathrm{mM}): \mathrm{NaCl} 122 ; \mathrm{NaHCO}_{3} 25 ; \mathrm{KCl} 4.7$; $\mathrm{KH}_{2} \mathrm{PO}_{4} 1.2 ; \mathrm{MgCl}_{2} 1.2 ; \mathrm{CaCl}_{2} 2.5$; and mannitol, 30. Osmolality ranged between 305 and $315 \mathrm{mosmol} / \mathrm{kg} \mathrm{H} \mathrm{H}_{2}$.

Toxin A was purified as described previously. ${ }^{19}$ Evan's blue was purchased from E Merck (Germany). The following drugs were used in the experiments: sodium pentobarbital (Mebumal; Apoteksbolaget, Umeå, Sweden), methohexital (Brietal; Eli Lilly, Sweden), nifedipine (Sigma Chemical Co., St Louis, Missouri, USA), hexamethonium (Sigma Chemical Co), and granisetron (Kytril; SmithKline Beecham, Sweden). All drugs except nifedipine were dissolved in saline. Nifedipine was dissolved in $70 \%$ ethanol in a concentration of $10 \mathrm{mg} / \mathrm{ml}$ diluted $5-7$ times in saline before intravenous administration to animals.

STATISTICAL ANALYSIS

Results are expressed as mean (SEM). The sign test or Wilcoxon matched pairs signed ranks test were used when testing statistical significance between paired observations.

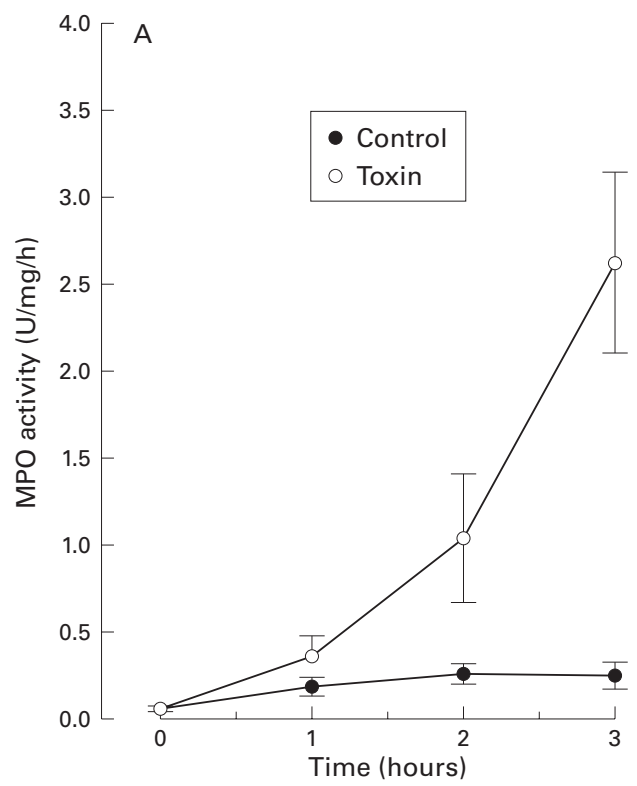

When comparing unpaired observations, the Mann-Whitney U test was used. A p level of 0.05 or less was considered to be statistically significant.

\section{Results}

MPO AND EVAN'S BLUE EXPERIMENTS

The time course of MPO release is shown in figs 1-4. Other measurements are given in tables 2 and 3. Statistical analyses were performed on observations made at three hours.

\section{Experiments on acutely denervated intestinal} segments

Tissue damage was estimated from the scoring system given in table 1 . The inflammatory response to toxin A was followed by measurements of the release of MPO into luminal fluid and tissue concentrations of Evan's blue. Estimations of MPO, which were made repeatedly during the course of the experiments, represent an indirect measure of accumulation of neutrophils in intestinal tissue. Tissue concentrations of Evan's blue bound to albumin reflects extravasation of protein as the intravascular content of labelled albumin was flushed with a large volume of physiological saline. Measurements of Evan's blue were made at the end (three hours) of the experiments. Finally, the number of veins with RBCs was estimated, presumably reflecting the extent of venous congestion.

Experiments were performed with two luminal concentrations of toxin A, 1 or $15 \mu \mathrm{g} / \mathrm{ml}$. Both concentrations caused significant damage to the intestinal mucosa (table 2). With the scoring system used, no statistically significant differences were demonstrated between the two toxin concentrations.

It is evident from figs 1 and 2 that release of MPO into the intestinal lumen increased

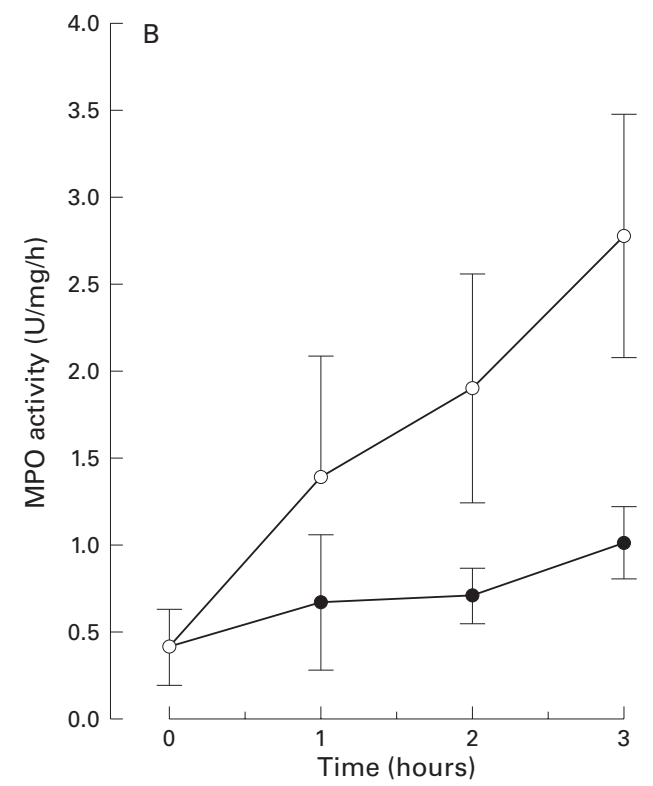

Figure 1 Effect of Clostridium difficile toxin A ( $1 \mu \mathrm{g} / \mathrm{ml}$ physiological saline) on myeloperoxidase (MPO) activity in the intestinal lumen at various times after exposing one segment to the toxin. A control segment was only exposed to. physiological saline. (A) Experiments $(n=6)$ in which the intestines were acutely denervated by cutting the periarterial nerves. (B) Results from the experiments $(n=5)$ in which the intestines were denervated 4-6 weeks prior to the experiments ("chronic denervation"). Values are given as mean (SEM). 

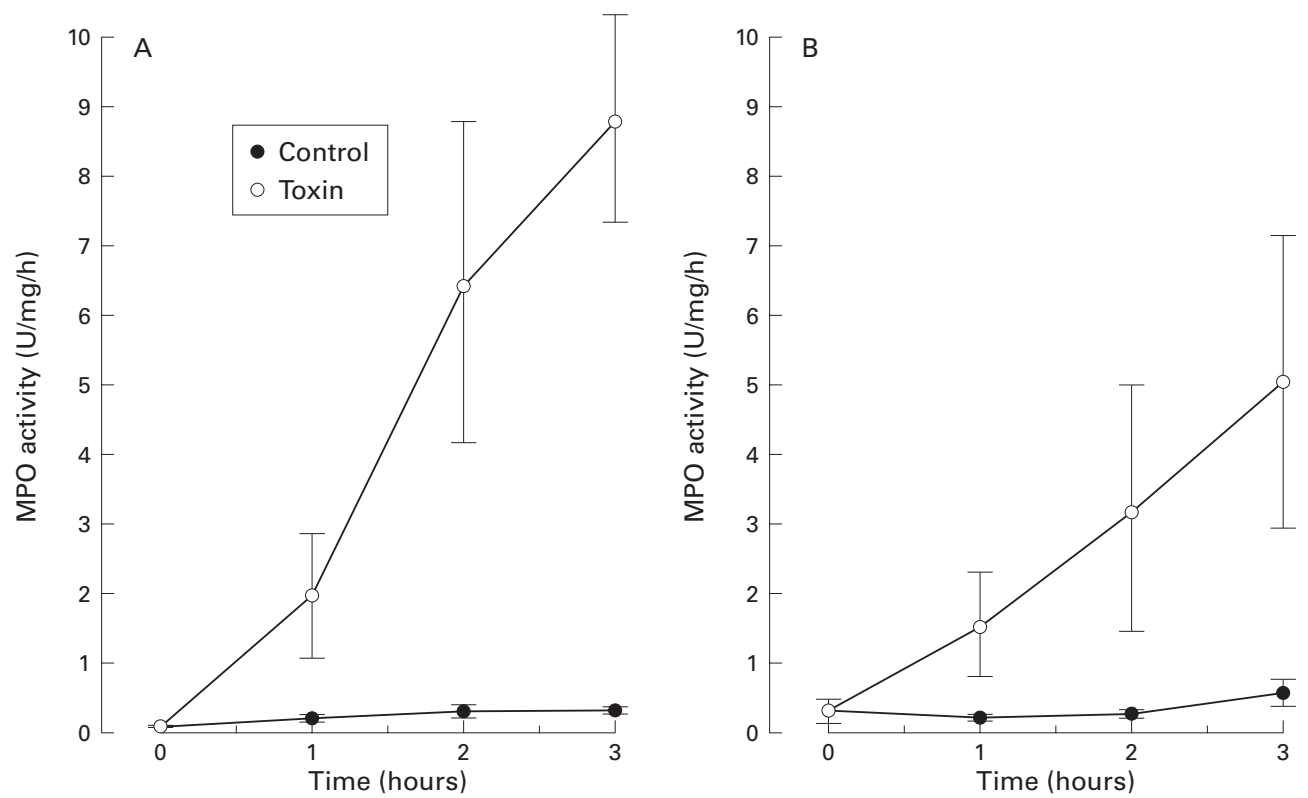

Figure 2 Effect of Clostridium difficile toxin A (15 $\mu \mathrm{g} / \mathrm{ml}$ physiological saline) on myeoloperoxidase activity (MPO) in the intestinal lumen at various times after exposing one segment to the toxin. A control segment was only exposed to physiological saline. $(A)$ Experiments $(n=6)$ in which the intestines were acutely denervated by cutting the periarterial nerves. (B) Results from experiments $(n=5)$ in which the intestines were denervated 4-6 weeks prior to the experiments ("chronic denervation"). Values are given as mean (SEM).

throughout the experiment in the segments exposed to the toxin whereas MPO release in the control segments remained unchanged. At three hours, MPO release was significantly higher in the toxin segment compared with that of the control segment, regardless of the concentration of toxin used. The high toxin concentration evoked a significantly larger release of MPO than the low concentration (table 3).

Extravasation of Evan's blue was significantly greater in the toxin segments than in the corresponding control segments (table 3). Comparing the effects of high and low toxin concentrations, no statistically significantly differences were demonstrated. Accumulation of RBCs was significantly greater in the intestinal segments exposed to toxin A than in the corresponding control segments although no difference was seen between the two toxin concentrations used (table 2).

Table 3 Release of myeloperoxidase activity (MPO, U/mg/h) into the intestinal lumen and tissue content of Evans blue (pmol/mg) in control segments and intestinal segments exposed to toxin $A$ for three hours in the different series of experiments. Hexamethonium and nifedipine exeperiments were performed on acutely denervated intestinal segments

\begin{tabular}{|c|c|c|c|c|}
\hline \multirow[b]{2}{*}{ Series } & \multicolumn{2}{|l|}{ MPO release } & \multicolumn{2}{|c|}{ Evans blue concn } \\
\hline & Control & Toxin $A$ & Control & Toxin $A$ \\
\hline \multicolumn{5}{|l|}{ Toxin A, $1 \mu \mathrm{g} / \mathrm{ml}$} \\
\hline Acutely denervated (6) & $0.26(0.06)$ & $2.63(0.52)^{\mathrm{a}}$ & $32(2)$ & $52(10)^{\mathrm{a}}$ \\
\hline Chronically denervated (5) & $1.02(0.21)^{\mathrm{b}}$ & $2.79(0.70)^{\mathrm{a}}$ & $30(2)$ & $48(4)^{a}$ \\
\hline Hexamethonium (5) & $0.29(0.05)$ & $0.80(0.20)^{\mathrm{a} b \mathrm{c}}$ & $30(12)$ & $36(13)^{a}$ \\
\hline Nifedipine (6) & $0.51(0.13)$ & $1.06(0.26)^{\mathrm{bc}}$ & $20(2)^{b c}$ & $34(10)$ \\
\hline \multicolumn{5}{|l|}{ Toxin A, $15 \mu \mathrm{g} / \mathrm{ml}$} \\
\hline Acutely denervated (6) & $0.33(0.06)$ & $8.83(1.48)^{\mathrm{ad}}$ & $29(3)$ & $68(10)^{\mathrm{a}}$ \\
\hline Chronically denervated (5) & $0.55(0.19)$ & $5.02(2.1)^{\mathrm{a}}$ & $33(4)$ & $76(5)^{\mathrm{a} d}$ \\
\hline
\end{tabular}

Numbers in parentheses indicate number of observations.

${ }^{a}$ Statistically significant compared with control; ${ }^{b}$ statistically significant compared with acutely denervated; ${ }^{\text {c }}$ statistically significant compared with chronically denervated; ${ }^{\mathrm{d}}$ statistically significant compared with corresponding group of toxin $\mathrm{A}, 1 \mu \mathrm{g} / \mathrm{ml}$.
Experiments on chronically denervated intestinal segments

Involvement of extrinsic afferent nerves in the inflammatory response to toxin A was investigated in one series of experiments by denervating the small intestine $4-6$ weeks prior to the acute experiments. This procedure allows the periarterial intestinal nerves with their cell bodies outside the intestinal wall to degenerate, as demonstrated with histochemical methods in other studies from our laboratory. ${ }^{72021}$

Mucosal damage caused by toxin A at low concentrations was less extensive in the segments chronically denervated than in segments acutely denervated. No difference between acutely and chronically denervated segments was demonstrated when the intestinal segment was exposed to the higher toxin concentration (table 2).

Despite the effect on mucosal morphology in the low toxin experiments, no statistically significant difference in luminal MPO release was evident between corresponding toxin segments in acutely and chronically denervated animals (figs 1, 2; table 3). MPO activity in control segments was significantly higher in chronically than in acutely denervated segments. Tissue concentrations of Evan's blue were significantly higher in segments exposed to toxin A than in their corresponding control segments (table 3 ). No statistically significant differences were seen between corresponding toxin segments in acutely and chronically denervated animals. Thus chronic denervation failed to influence luminal release of MPO and extravasation of Evan's blue in response to a low toxin A concentration yet mucosal damage was less pronounced after chronic denervation. The high toxin concentration induced significantly more marked extravasation of Evan's 


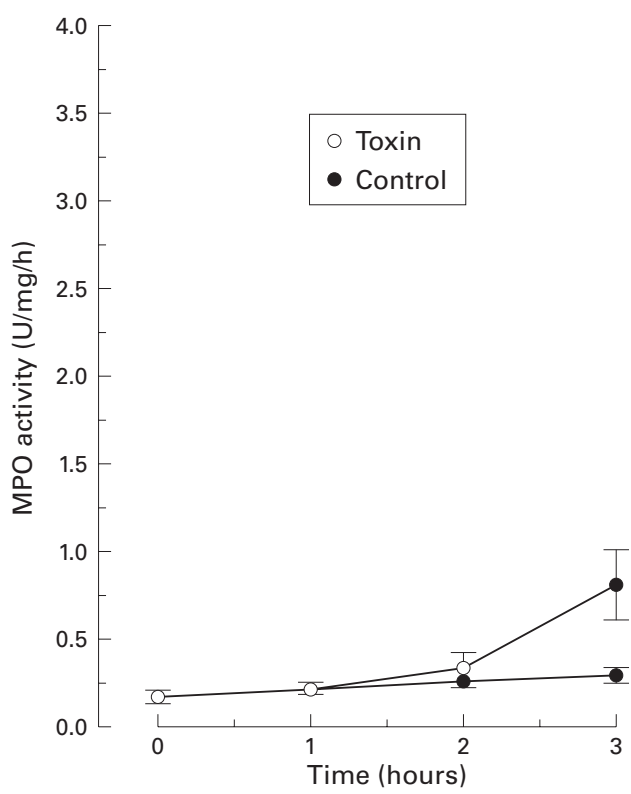

Figure 3 Effect of Clostridium difficile toxin A (1 $\mu \mathrm{g} / \mathrm{ml}$ physiological saline) on myeoloperoxidase activity (MPO) in the lumen of acutely denervated intestinal segments of animals pretreated with hexamethonium, a nicotinic receptor blocker. $M P O$ activity at various times after exposing one segment to the toxin is shown. A control segment was only exposed to physiological saline. MPO activity response to the toxin was markedly attenuated by the drug (compare figs 1 and 3). Values are mean (SEM); $n=5$.

blue than low concentrations (table 3 ). Comparing the effects of low and high toxin concentrations on MPO release, no statistically significant difference was seen. Similar observations were made with regard to the number of RBCs contained in the intestinal veins.

\section{Hexamethonium experiments}

In another series of experiments, hexamethonium, a nicotinic receptor blocker, was used. This compound has been shown to markedly attenuate fluid secretion in the intestine caused by a wide variety of secretagogues. ${ }^{22}$ The drug (10 $\mathrm{mg} / \mathrm{kg}$ body weight) was given prior to toxin A $(1 \mu \mathrm{g} / \mathrm{ml})$ administration and then repeatedly every 45 minutes throughout the experiments to maintain receptor blockade. Villus damage was less extensive than in control animals but larger than seen in chronically denervated animals. Hexamethonium did not prevent the increase in MPO release caused by exposing the intestinal mucosa to the toxin (fig 3; table 3). However, the increase in MPO release was significantly smaller than MPO release in experiments in which no drugs were given (table 3).

Although mean tissue concentrations of Evan's blue were lower in the hexamethonium experiments than in experiments not using the drug (toxin A concentration $1 \mu \mathrm{g} / \mathrm{ml}$ ), the difference was not statistically significant (table 3). After giving hexamethonium, the number of veins containing RBCs was the same in the control segment and the segment exposed to the toxin. Furthermore, compared with acutely denervated animals, the toxin segment of hexamethonium treated rats had fewer veins containing RBCs.

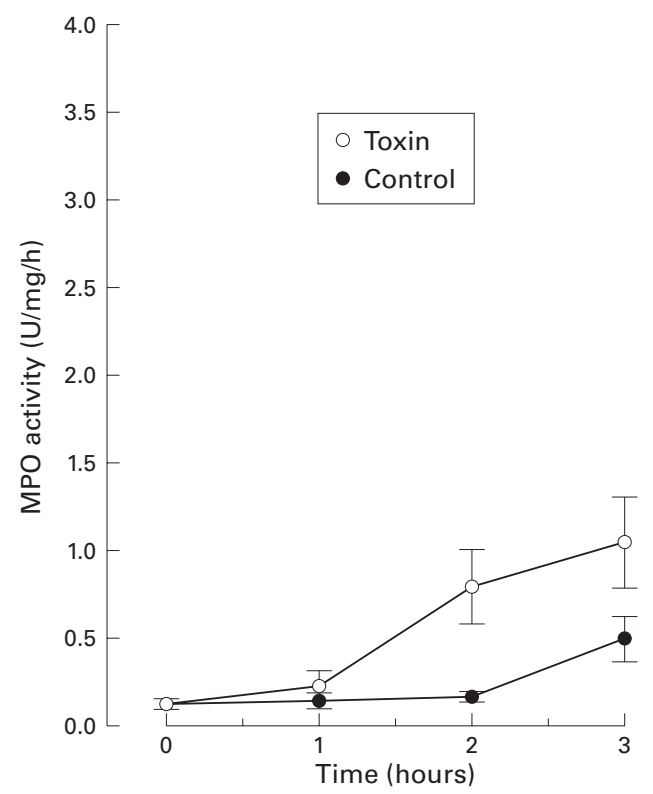

Figure 4 Effect of Clostridium difficile toxin A (1 $\mu \mathrm{g} / \mathrm{ml}$ physiological saline) on myeoloperoxidase activity (MPO) in the intestinal lumen in animals pretreated with nifedipine, a blocker of calcium channels of the L-type. Intestinal segments were acutely denervated. MPO activity at various times after exposing one segment to the toxin is shown. A control segment was only exposed to physiological saline. MPO activity response to the toxin was markedly attenuated by the drug (compare figs 1 and 4). Values are mean (SEM); $n=6$.

Nifedipine experiments

The effect of the calcium channel blocker nifedipine $(2 \mathrm{mg} / \mathrm{kg}$ body weight) prior to administering toxin $\mathrm{A}(1 \mu \mathrm{g} / \mathrm{ml})$ and every 45 minutes throughout the experiments was tested in five experiments. Villi were damaged to the same extent as in animals not receiving the drug. No difference in MPO release between control and toxin segments was demonstrated when nifedipine was given (fig 4, table 3). Furthermore, release measured at three hours was significantly lower in the nifedipine experiments compared with experiments in which no drug was given (table 3 ).

In animals who received nifedipine there was no statistically significant difference between control and toxin segments with regard to Evan's blue concentrations (table 3). Furthermore, in control segments, Evan's blue concentrations were significantly lower in the nifedipine series than in the corresponding segments in animals not receiving any drug (acutely or chronically denervated segments).

\section{GRAVIMETRIC EXPERIMENTS}

Hexamethonium experiments

The gravimetric technique for measuring net fluid transport was used in six experiments to investigate the effect of hexamethonium on net fluid secretion evoked by toxin A $(15 \mu \mathrm{g} / \mathrm{ml})$. Within two hours of administration of toxin A, control net fluid transport (1 (17) $\mu \mathrm{l} / \mathrm{min} / 100$ $\mathrm{cm}^{2}$ ) became net fluid secretion (175 (28) $\left.\mu \mathrm{l} / \mathrm{min} / 100 \mathrm{~cm}^{2} ; \mathrm{p}<0.05\right)$. Hexamethonium (10 $\mathrm{mg} / \mathrm{kg}$ body weight) given as a single dose intravenously returned fluid transport to control (5 (18) $\left.\mu \mathrm{l} / \mathrm{min} / 100 \mathrm{~cm}^{2} ; \mathrm{p}<0.05\right)$ within minutes. The effects of hexamethonium have 
Table 4 Summary of the results of the study. Four variables were studied: villus morphology, luminal myeoloperoxidase activity (MPO), the presence of red blood cells $(R B C)$ in intestinal veins, and accumulation of Evan's blue in the intestinal tissue. The effects of the different experimental procedures were judged compared with observations made in control experiments performed on acutely denervated intestines. Experiments were carried out using a low $(1 \mu \mathrm{g} / \mathrm{ml})$ or high $(15 \mu \mathrm{g} / \mathrm{ml})$ concentration of Clostridium difficile toxin A. Hexamethonium (Hex) and nifedipine (Nif) experiments were performed on acutely denervated (dener.) intestinal segment

\begin{tabular}{llllll}
\hline & \multicolumn{2}{l}{ Low toxin } & & High toxin \\
\cline { 2 - 3 } & Hex & Nif & Chronic dener. & & Chronic dener. \\
\hline Morphology & - & 0 & - & 0 \\
MPO & - & - & 0 & \\
RBC & - & - & - & \\
Evan's blue & 0 & 0 & 0 & & 0 \\
\hline
\end{tabular}

-, attenuation of response to toxin $\mathrm{A} ; 0$, no effect on response to toxin $\mathrm{A}$.

been tested repeatedly on control segments in this laboratory (for example, see Cassuto and colleagues $^{23}$, Karlström and colleagues, ${ }^{24}$ and Jodal and colleagues ${ }^{25}$ ). Fluid transport was increased in the absorptive direction. However, the effect was much smaller than that seen in the present experiments. Experiments showing that intestinal net fluid transport remained unaltered during a two hour observation period have been reported previously (see Karlström ${ }^{7}$ ).

\section{Nifedipine experiments}

Nifedipine was given to animals $(n=5)$ in the same way as hexamethonium - that is, when toxin A had evoked a fluid secretory response. The dose used $(2 \mathrm{mg} / \mathrm{kg})$ has been shown to markedly inhibit fluid secretion evoked by CT and bile salt. ${ }^{1426}$ No consistent drug effect on fluid transport was demonstrated (data not shown).

\section{Granisetron experiments}

Granisetron, a 5-hydroxytryptamine $(5-\mathrm{HT})_{3}$ receptor blocker, was administered in five experiments intravenously $(40 \mu \mathrm{g} / \mathrm{kg}$ body weight) in the same way as hexamethonium. This dose has been shown to attenuate intestinal fluid secretion ${ }^{27}$ and duodenal alkaline secretion $^{28}$ caused by CT. No effect was observed on net fluid secretion evoked by toxin A (204 (66) and 225 (91) $\mu 1 / \mathrm{min} / 100 \mathrm{~cm}^{2}$ before and after the drug, respectively; control absorption 50 (1) $\mu 1 / \mathrm{min} / 100 \mathrm{~cm}^{2}$ )

\section{Discussion}

Using three different compounds that in different ways attenuated nervous activity within the enteric nervous system (ENS), Castagliuolo and colleagues ${ }^{13}$ demonstrated convincingly that the ENS was involved in the intestinal response to Clostridium difficile toxin A. The study by Castagliuolo et al represented the starting point of the present series of experiments and our observations confirm, generally speaking, the work of the Boston group. As indicated in the introduction, one major aim of our study was to investigate the possible involvement of axon reflexes in the response using a different experimental approach than that used by Castagliuolo et al. Another aim was to investigate if the nervous involvement was similar when exposing the intestinal mucosa to a low or comparatively high concentration of toxin A. Three biochemical markers of inflammation (luminal release of MPO, tissue accumulation of Evan's blue, and RBCs in intestinal veins) were studied. Table 4 summarises the results of our study.

POSSIBLE INVOLVEMENT OF AN AXON REFLEX IN THE INTESTINAL RESPONSE TO TOXIN A

It is well established that there exists reflexes in the ENS that are confined to the intestinal wall ("intramural reflexes"). The peristaltic reflex is an example of such a reflex. There is also experimental evidence for the existence of gastrointestinal axon reflexes controlling, for example, blood flow. ${ }^{5}$ To investigate the possible involvement of axon reflexes in the inflammatory response to toxin $\mathrm{A}$, the extrinsic nervous supply to the intestinal segments was severed 4-6 weeks prior to the acute experiments. This procedure destroys axons with their cell somas proximal to the site of division. In line with this we have shown in previous studies that adrenergic innervation of the small intestine is eliminated with this procedure. ${ }^{72021}$ Furthermore, axon reflexes with their sensory nerve endings in the intestinal wall and cell somas in the dorsal root ganglia should be destroyed. In the present study it was demonstrated that chronic denervation did not influence levels of two of the inflammatory markers (luminal MPO release and Evan's blue tissue concentrations) in segments exposed to the toxin whereas the third marker (number of RBCs in veins) was significantly lower than in acutely denervated intestinal segments. The results were similar with the two concentrations of toxin tested ( 1 and $15 \mu \mathrm{g} / \mathrm{ml}$ ).

Although chronic denervation did not influence the inflammatory indicators in the segments exposed to toxin, the morphological changes in the villi (table 1) evoked by the lower toxin A concentrations were significantly attenuated by chronic denervation. In fact, chronic denervation prevented more or less completely the morphological changes caused by $1 \mu \mathrm{g}$ toxin $\mathrm{A} / \mathrm{ml}$ (table 2 ). When the intestinal mucosa was exposed to the high toxin A concentration, intestinal chronic denervation did not prevent villus damage. Taken together these observations suggest that an axon reflex may participate in the development of villus damage when toxin concentrations in the intestinal lumen are comparatively low, although the inflammatory response is not attenuated (MPO release and Evan's blue accumulation; table 4 ). At higher toxin concentrations, the morphological effects of the toxin itself seem to be so great as to override the beneficial effects of chronic denervation.

In the study by Castagliuolo and colleagues, ${ }^{13}$ the possible involvement of an axon reflex in the intestinal toxin A response was investigated in another manner than in the present investigation. They treated rats with capsaicin in increasing doses two weeks prior to the acute experiment. According to the current dogma, capsaicin depletes thin sensory afferents of their neurotransmitters. This procedure prevented the increase in MPO activity in the intestinal lumen and increased mannitol permeability of the intestinal epithelium caused by 
the toxin. Hence according to Castagliuolo et al an axon reflex was involved in the effect of the toxin on extravasation of neutrophils into the intestinal lumen. The reason for the difference between the present results and those of Castagliuolo et al is not known. One possible factor should be pointed out. The effect of the toxin on intestinal morphology was judged by the same scheme in the two studies. Damage caused by the toxin in the American study $(5 \mu \mathrm{g}$ to a $5 \mathrm{~cm}$ long segment) was significantly less pronounced than that seen in the present study $(1 \mu \mathrm{g} / \mathrm{ml}$ toxin - that is, about $1 \mu \mathrm{g}$ per segment) indicating that the toxin used by us may have been more potent. Hence the results of the two studies may not be strictly comparable.

It might be argued that toxin absorbed by the intestine may influence the function of the corresponding control segment. If that had been the case one would have expected to see a difference between control segments in the experiments with low and high toxin concentrations. No such difference was seen for any variable.

\section{HEXAMETHONIUM AND THE INFLAMMATORY} RESPONSE TO TOXIN A

Most of the experiments in this study were performed on intestinal segments that had been acutely denervated by cutting the periarterial nerves. It was therefore possible to investigate involvement of intramural reflexes in the response to toxin A using hexamethonium, a nicotinic receptor blocker, as it is usually assumed that axon reflexes do not contain any cholinergic synapses. Furthermore, the systemic effects of the drug cannot influence intestinal functions as the intestines were denervated. Hexamethonium has been shown to attenuate fluid secretion in the small intestine evoked by a large number of secretagogues, including several enterotoxins, inflammatory mediators, and inflammation itself (for a review see Jodal and Lundgren ${ }^{22}$ ). The effect of hexamethonium was investigated with regard to the inflammatory indicators of the present study. For two of the indicators (MPO release and venous RBC accumulation) it was shown that the increase caused by the toxin was significantly attenuated by hexamethonium. In fact, in the hexamethonium experiments, MPO release was about one third of that recorded in the acutely denervated segments exposed to toxin A. With regard to tissue concentrations of Evan's blue, it was not possible to demonstrate any significant difference between animals given hexamethonium and acutely denervated control animals (tables 2, 4).

From the discussion above, one may propose that the nervous involvement in the response to toxin A may consist of two "parts", as depicted in fig 5. According to this speculative hypothesis, the toxin first evokes an inflammatory response which eventually may lead to overt tissue damage. It is proposed that intramural reflexes are involved in the inflammatory response, as judged by the effect of hexamethonium on MPO release and indirectly also on the effect of the toxin on tissue morphology. The inflammation activates an axon reflex(es)

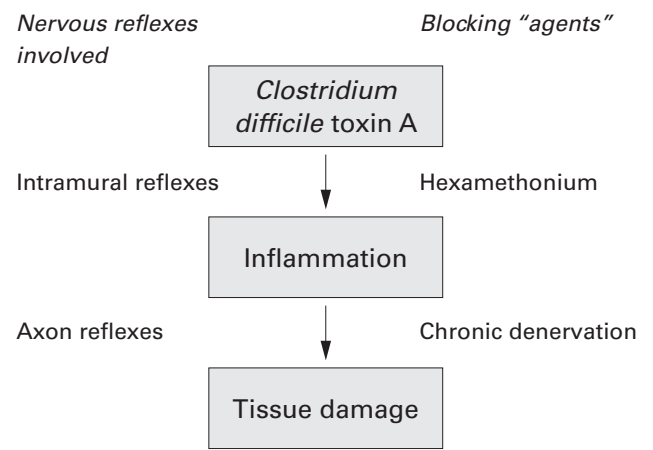

Figure 5 Hypothetical model based on the findings of the present study. Nerves participate both in the development of the inflammatory response and in the events leading to tissue damage, at least when toxin concentrations are not too high. The results of the present study suggest that an intramural reflex(es) is involved in the toxin response leading to inflammation whereas an axon reflex(es) participates in the development of tissue damage.

which in turn participates in the destruction of the intestinal mucosa. The latter effect may, at least in part, be mediated by an axon reflex control of mast cells as suggested by several observations of Pothoulakis and collaborators. ${ }^{29}$

THE MECHANISM UNDERLYING THE EFFECT OF TOXIN A ON INTESTINAL FLUID TRANSPORT In agreement with earlier observations it was shown in this study that after administration of hexamethonium, fluid secretion became fluid absorption when given during ongoing secretion in response to a high toxin concentration. The effect of hexamethonium is probably explained by the presence of a cholinergic influence on the secretory neurones in the submucous plexus of the ENS. ${ }^{30}$ This synaptic cholinergic influence is effectively blocked by nicotinic receptor antagonists such as hexamethonium.

In the case of the cholera enterotoxins several lines of evidence suggest that the toxin activates the ENS, at least in part, via release of 5-HT from enterochromaffin cells. ${ }^{22}$ In line with this it has been shown that $5-\mathrm{HT}_{3}$ receptor antagonists partly inhibit fluid secretion caused by CT. ${ }^{27}{ }^{31}$ Granisetron, a blocker of this type of serotonin receptor, was tested in this study. No effect on fluid secretion evoked by toxin A was demonstrated.

There are marked differences between toxin A and CT with regard to histological changes caused by the toxins. Exposing the intestinal mucosa to toxin $\mathrm{A}$ is accompanied by a pronounced inflammatory response whereas this is not seen after exposure to CT. Therefore, the lack of effect of granisetron on toxin A evoked fluid secretion may be explained by the ENS being stimulated not by 5 -HT but by inflammatory mediators in the toxin A experiments, many of which are known to activate enteric nerves (see for example Brunsson and colleagues ${ }^{32}$ ).

\section{EVAN'S BLUE LABELLED ALBUMIN AND} INFLAMMATION

Extravasation of Evan's blue labelled albumin presumably reflects increased capillary permeability to large proteins, explained by an 
increase in size of capillary pores. The present results suggest that this variable was not under nervous control (table 4), indicating that the increase in capillary albumin permeability was evoked by the inflammatory response itself. It is well known that inflammation leads to accumulation of several biologically active compounds that increase capillary pore size. ${ }^{34}$

Toxin A evokes a pronounced inflammatory response, including a marked change in intestinal morphology. Nellgård and collaborators ${ }^{35}$ investigated Evan's blue extravasation in association with less severe inflammation caused by intestinal obstruction. They demonstrated that the increased tissue concentration of Evan's blue in association with inflammation was decreased by exposing the intestinal serosa to lidocaine, a local anaesthetic. It is therefore possible that nervous mechanisms may also evoke extravasation of albumin. However, toxin $\mathrm{A}$ in high enough concentrations may induce inflammation in which locally produced inflammatory mediators may be so dominating that a nervous involvement cannot be demonstrated experimentally.

\section{CALCIUM CHANNEL BLOCKADE}

Voltage gated calcium channels play a significant role in many cellular events, such as neurotransmitter release and muscle contractions. There are at least four different types of channels, termed L, N, P, and Q channels. ${ }^{36}$ Several studies have shown that L-type calcium channel blockers in particular inhibit intestinal fluid secretion evoked by CT, ${ }^{14}$ at least in part via inhibition of 5-HT release from enterochromaffin cells. In this study we obtained experimental evidence that nifedipine influenced the inflammatory response caused by toxin $\mathrm{A}$. The drug attenuated MPO activity in the intestinal lumen whereas there was no effect on tissue morphology or accumulation of Evan's blue. To what extent these effects can be ascribed to changes in ENS functions cannot be ascertained from the present results. The tissue response to toxin $\mathrm{A}$ is so complex that non-nervous effects of nifedipine are also possible.

In conclusion, the results of the present study indicate that the ENS plays an important role in the development of the intestinal inflammatory response to Clostridium difficile toxin A when the toxin concentration is $1 \mu \mathrm{g} / \mathrm{ml}$. Based on our observations we suggest a hypothetical model in which nerves play a role in two steps in the tissue response to the toxin: intramural nerves are important for the development of the inflammatory response whereas axon reflexes contribute to the tissue damage that accompanies the toxin evoked inflammation. In contrast, exposing the intestinal mucosa to a toxin concentration of 15 $\mu \mathrm{g} / \mathrm{ml}$ evokes an inflammatory response in which nerves do not seem to be important. Fluid secretion evoked by high toxin concentrations, on the other hand, seems to be mediated by enteric nerves.

This research was supported by a grant from the Swedish Medical Research Council (2855). Christoph von EichelStreiber generously supplied us with Clostridium difficile toxin A. The authors gratefully acknowledge the excellent technical
assistance of Ms Ann-Sofie Gundersen.

1 Cassuto J, Jodal M, Tuttle R, et al. On the role of intramural astes in nerves in the pathogenesis of cholera toxin-induced inte

2 Eklund S, Jodal M, Lundgren O. The enteric nervous system participates in the secretory response to the heat table enterotoxins of Escherchia coli in rats and cats. Neuroscience 1985;14:673-81.

3 Karlström L, Cassuto J, Jodal M, et al. The importance of the enteric nervous system for the bile salt-induced secretion in the small intestine of the rat. Scand $\mathcal{F}$ Gastroenterol 1983;18:117-23.

4 Brunsson I. Enteric nerves mediate the fluid secretory response due to Salmonella typhimurium R5 infection in the rat small intestine. Acta Physiol Scand 1987;131:60917 .

5 Holzer P. Local effector functions of capsaicin-sensitive sensory nerve endings: involvement of tachykinins, calcitonin gene-related peptide and other neuropeptides. Neuroscience 1988;24:739-68.

6 Rozsa ZS, Sharkey KA, Jansco G, et al. Evidence for a role of capsaicin-sensitive mucosal afferent nerves in the regulacapsaicin-sensitive mucosal afferent nerves in the regula-
tion of mesenteric blood flow in the dog. Gastroenterology 1986;90:906-10.

7 Karlström L. Mechanisms in bile salt-induced secretion in the small intestine of the rat. Acta Physiol Scand 1986;126(suppl) 549 .

8 Sjöqvist A. Interaction between antisecretory opioid and sympathetic mechanisms in the rat small intestine. Acta Physiol Scand 1991;142:127-32.

9 Fiorentini C, Thelestam M. Clostridium difficile toxin A and its effects on cell. Toxicon 1991;29:543-67.

10 Arnon SS, Mills DC, Day PA, et al. Rapid death of infant rhesus monkeys injected with Clostridium difficile toxins A and $\mathrm{B}$ : physiologic and pathologic basis. 7 Pediatr 1984;104:34-40.

11 Thelestam M, Florin I, Olarte EC. Clostridium difficile toxins. In: Aktories K, ed. Bacterial toxins: a laboratory companion. London: Chapman and Hall, 1996.

12 Riegler M, Sedivy R, Pothoulakis C, et al. Clostridium difficile toxin $\mathrm{B}$ is more potent than toxin $\mathrm{A}$ in damaging cile toxin B is more potent than toxin A in damaging
human colonic epithelium. 7 Clin Invest 1995;95:2004-11.

3 Castagliuolo I, LaMont JT, Letourneau R, et al. Neuronal involvement in the intestinal effects of Clostridium difficile toxin A and Vibrio cholerae enterotoxin in rat ileum. Gastroenterology 1994;107:657-65.

14 Timar Peregrin A, Ahlman H, Jodal M, et al. Effects of calcium channel blockade on intestinal fluid secretion: sites of action. Acta Physiol Scand 1997;160:379-86.

5 Gamse R, Holzer P, Lembeck F. Decrease of substance P in primary afferent neurons and impairment of neurogenic plasma extravasation by capsaicin. Br F Pharmacol 1980;68: 207-13.

16 Schierwagen C, Bylund-Fellenius A-C, Lundberg C. Improved method for quantification of tissue PMN accumulation measured by myeloperoxidase activity. $f$ Pharmacol Methods 1990;23:179-86.

17 Bradley PP, Priebat DA, Christensen RD, et al. Measurement of cutaneous inflammation: estimation of neutrophil content with an enzyme marker. F Invest Dermatol 1982;78: 206-9.

18 Cassuto J, Jodal M, Tuttle R, et al. 5-Hydroxytryptamine and cholera secretion. Scand f Gastroenterol 1982;17:695703.

19 von Eichel-Streiber C, Harperath U, Bosse D, et al. Purification of two high molecular weight toxins of Clostridium difficile which are antigenically related. Microb Pathog 1987;2:307-18

20 Jodal M, Holmgren S, Lundgren $\mathrm{O}$, et al. A. Involvement of the myenteric plexus in the cholera toxin-induced net fluid secretion in the rat small intestine. Gastroenterology 1993;105:1286-93.

21 Timar Peregrin A, Svensson M, Ahlman H, et al. The effects on net fluid transport of noxious stimulation of the jejunal mucosa in anaesthetized rats. Acta Physiol Scand 1999;166: $55-64$.

22 Jodal M, Lundgren O. Neural reflex modulation of intestinal epithelial transport. In: Gaginella TS, ed. Regulatory mechanisms in gastrointestinal function. Boca Raton, Fa: CRC mechanisms in gastroin

23 Cassuto J, Jodal M, Lundgren O. The effect of nicotinic and muscarinic receptor blockade on cholera toxin induced intestinal secretion in rats and cats. Acta Physiol Scand 1982;114:573-7.

24 Karlström L, Cassuto J, Jodal M, Lundgren O. Involvement of the enteric nervous system in the intestinal secretion induced by sodium deoxycholate and sodium ricinoleate. Scand $\mathcal{F}$ Gastroenterol 1986;21:331-40.

25 Jodal M, Wingren U, Jansson $M$ et al. Nerve involvement in fluid transport in the inflamed rat jejunum. Gut 1993;34: 1526-30.

26 Timar Peregrin A, Ahlman H, Jodal $\mathrm{M}$ et al. Involvement of serotonin and calcium channels in the intestinal fluid secretion evoked by bile salt and cholera toxin $\mathrm{Br} F$ Pharmacol 1999;127:887-94.

27 Sjöqvist A, Cassuto J, Jodal M, et al. Actions of serotonin antagonists on cholera-toxin-induced intestinal fluid secreantagonists on cholera-toxin-induced intes
tion. Acta Physiol Scand 1992;145:229-37.

28 Jaup EA, Timar Peregrin A, Jodal M, et al. Nervous control of alkaline secretion in the duodenum as studied by the use of cholera toxin in the anaesthetized rat. Acta Physiol Scand 1998;162:165-74. 
29 Pothoulakis C, Castagliuolo I, LaMont JT. Nerves and intestinal mast cells modulate responses to enterotoxins. intestinal mast cells mor
NIPS 1998;13:58-63.

30 Bornstein JC, Furness JB, Costa M. Sources of excitatory synaptic inputs to neurochemically identified submucous neurons of guinea-pig small intestine. F Auton Nerv Syst 1987;18:83-91.

31 Beubler E, Horina G. 5- $\mathrm{HT}_{2}$ and $5-\mathrm{HT}_{3}$ receptor subtypes mediate cholera-toxin- induced intestinal fluid secretion in the rat. Gastroenterology 1990;99:83-9.

32 Brunsson I, Sjöqvist A, Jodal M, et al. Mechanisms underlying the intestinal fluid secretion evoked by nociceptive
serosal stimulation of the rat. Naunyn Schmiedebergs Arch Pharmacol 1985;328:439-45.
33 Brunsson I, Sjöqvist A, Jodal M, et al. Mechanisms underlying the small intestinal fluid secretion caused by arachidonic acid prostaglandin $\mathrm{E}_{1}$ and prostaglandin $\mathrm{E}_{2}$ in the rat in vivo. Acta Physiol Scand 1987;130:633-42.

34 Lum H, Malik AB. Mechanisms of increased endothelial permeability. Can F Physiol Pharmacol 1995;74:787-800.

35 Nellgård P, Jonsson A, Bojo L, et al. Small-bowel obstruction and the effects of lidocaine, atropine and hexamethonium on inflammation and fluid losses. Acta Anaesamethonium on inflammation

36 Tsien RW, Lipscombe D, Madison DV, et al. Multiple types of neuronal calcium channels and their selective modulation. TINS 1988;11:431-8. 